\title{
Involvement of Respiratory Muscles During the Timed Inspiratory Effort Index Measurement With Surface Electromyography
}

\author{
Helson Lino Leite de Souza Costa, Leonardo Cordeiro de Souza, Arthur Evangelista da Silva Neto, \\ Bruno Leonardo da Silva Guimarães, Leandro Miranda de Azeredo, Marcos David Parada Godoy, \\ and Jocemir Ronaldo Lugon
}

\begin{abstract}
BACKGROUND: Mechanical ventilation is a life-support therapy that can be associated with respiratory muscle dysfunction that may perturb the weaning process. The timed inspiratory effort (TIE) index is a recently proposed weaning index that has been reported to be effective in predicting successful weaning. We sought to analyze the respiratory muscle groups involved with the TIE index measurement utilizing the surface electromyography (sEMG). METHODS: We conducted a prospective observational study including 46 mechanically ventilated subjects. The variable analyzed with SEMG was the root mean square (RMS) for correlation with the degree of recruitment of motor units and strength. The data were obtained along the $60 \mathrm{~s}$ of the TIE index measurement and analyzed in each one of the 3 20-s intervals. Pooled and individual muscle RMS values were analyzed comparing success and failure groups. $P<.05$ was considered significant. RESULTS: The median (interquartile range) age of the participants was 80 (71-87) y. The pooled SEMG data showed that muscle strength increased over time, following the profile observed for maximum inspiratory pressure, irrespective of the analyzed group. However, in line with the findings regarding maximum inspiratory pressure, the RMS medians were statistically higher at every 20-s interval in the success group. Diaphragm strength increased over time, with values reaching statistically significant differences at the end of the observation period, but only in the success group. In addition, diaphragm strength was statistically higher during the whole test in the success group. Finally, there was a substantial increase in sternocleidomastoid strength over time after $40 \mathrm{~s}$ of observation, which was not observed in the scalene muscles. CONCLUSIONS: Subjects succeeding in a weaning trial had higher muscle strength, confirmed in the pooled and the individual SEMG analysis. A vigorous diaphragm with low fatigue potential seems essential for successful weaning; the sternocleidomastoid may also be of importance in this regard. Key words: weaning; liberation; mechanical ventilation; surface electromyography; respiratory muscles. [Respir Care 2020;65(12):1857-1863. (c) 2020 Daedalus Enterprises]
\end{abstract}

\section{Introduction}

The failure of the weaning process represents a significant clinical and economic problem. ${ }^{1}$ Prolonged mechanical

\footnotetext{
Mr de Souza Costa, Mr da Silva Neto, Mr da Silva Guimarães, Mr de Azeredo, and Mr Godoy are affiliated with the Medical Science Postgraduate Program, Universidade Federal Fluminense, Niterói, Rio de Janeiro, Brazil. Dr de Souza is affiliated with the Physiotherapy College, Universidade Estácio de Sá, Niterói, Rio de Janeiro, Brazil. Dr de Souza and Mr da Silva Neto are affiliated with the Intensive Care Division, Hospital Icaraí, Niterói, Rio de Janeiro, Brazil. Dr de Souza and Mr Godoy are affiliated with the Intensive Care Division, Hospital
}

ventilation has been associated with several complications, such as ventilator-associated pneumonia, ventilator-induced diaphragmatic dysfunction, and ICU-acquired weakness. ${ }^{2-4}$ In recent studies, the timed inspiratory effort (TIE) index, a predictor for liberation from mechanical ventilation, has

\footnotetext{
\& Clínica São Gonçalo, São Gonçalo, Rio de Janeiro, Brazil. Dr Lugon is affiliated with the Medicine/Nephrology, Medical School of Universidade Federal Fluminense, Niterói, Rio de Janeiro, Brazil.

This work was partially supported by Estácio de Sá University by a research productivity program. The authors have disclosed no conflicts of interest.
} 
demonstrated higher accuracy and better performance in several scenarios in comparison with other indexes such as rapid shallow breathing index, maximum inspiratory pressure $\left(\mathrm{P}_{\text {Imax }}\right)$, and airway-occlusion pressure $0.1 \mathrm{~s}$ after the start of inspiration against an occluded airway. ${ }^{5-7}$

However, the assessment of respiratory muscle strength with $\mathrm{P}_{\text {Imax }}$ or the TIE index does not provide information about the involvement of the various respiratory muscle groups or the muscle strength generation during these measurements, leaving the degree of participation of each muscle segment largely unknown. Surface electromyography (sEMG) might be useful to identify the different respiratory muscle groups involved in the weaning process. $^{8-12}$

We hypothesized that the behavior of respiratory muscle groups may differ between patients who succeed or failed in a weaning trial from mechanical ventilation. We sought to analyze the mechanical relationships between the major respiratory muscle groups involved in the muscle strength generation during the TIE index measurement using sEMG analysis.

\section{Methods}

\section{Study Design}

We conducted an observational study in invasively ventilated subjects admitted to the adult ICU of the Icaraí Hospital, in Niterói, Brazil. This study was approved by the ethics committee of the University Hospital Antônio Pedro by Federal Fluminense University (CAAE: 61233416.0000.5243). Family members were informed about the study to obtain their consent for subject enrollment.

We recruited subjects with an artificial airway (ie, orotracheal tube or tracheostomy cannula) and receiving invasive mechanical ventilation for $>24 \mathrm{~h}$ who were clinically able to start the weaning process. Patients were excluded on the basis of the following criteria: hemoglobin $<10 \mathrm{~g} / \mathrm{dL}$, clinical or laboratory evidence of active infection, $\mathrm{S}_{\mathrm{aO}_{2}}<90 \%$, $\mathrm{F}_{\mathrm{IO}_{2}}>0.40$, hemodynamic instability (ie, heart rate $\geq 140$ beats/min, systolic blood pressure $<90$ or $>160 \mathrm{~mm} \mathrm{Hg}$ ), $\mathrm{P}_{\mathrm{aO}_{2}} / \mathrm{F}_{\mathrm{IO}_{2}}<150$, PEEP $>8 \mathrm{~cm} \mathrm{H} \mathrm{H}_{2} \mathrm{O}$, breathing frequency $>35$ breaths $/ \mathrm{min}$, tidal volume $<5 \mathrm{~mL} / \mathrm{kg}, \mathrm{pH}<7.3$, intracranial hypertension $>15 \mathrm{~mm} \mathrm{Hg}$, use of sedation, abdominal surgery at risk of evisceration, acute coronary artery disease, or unstable heart failure.

Correspondence: Leonardo Cordeiro de Souza PhD, Physiotherapy of Hospital Icaraí and Hospital \& Clínica São Gonçalo, Rua Marquês de Paraná, 233 - 5o. andar. CEP 24030-215 - Centro, Niterói - Rio de Janeiro, Brazil. E-mail: leonardo.uti@gmail.com.

DOI: $10.4187 /$ respcare. 07465

\section{QUICK LOOK}

\section{Current knowledge}

Liberation from mechanical ventilation requires assessments of respiratory muscle strength. The timed inspiratory effort (TIE) index has predicted success in ventilator weaning accurately. However, little is known about the mechanical relationships of the respiratory muscles with weaning outcomes. Surface electromyography can provide information about the degree of participation of each respiratory muscle group during tests for liberation from mechanical ventilation.

\section{What this paper contributes to our knowledge}

The diaphragm and sternocleidomastoid were the main muscles involved with positive outcomes on assessment with the TIE index. This information may allow for more specific programming of respiratory therapy for this population of critically ill patients.

All data were collected between August 2017 and March 2019 by one investigator. Both the TIE index measurement procedure and the sEMG were performed only on the days when the researcher in charge and first author of this study were present at the ICU. During this period, measurements of the TIE index under monitoring with sEMG were performed in 46 subjects. The intention was to deliberately choose a similar number of cases of success and failure among subjects who had undergone TIE index measurements under sEMG monitoring. Two subjects of the success group for technical problems with the signal of sEMG were excluded, thus resulting in 22 subjects successfully weaned for final analysis. None of the subjects in the failure group were excluded (Fig. 1).

\section{Measurement of the TIE Index}

A digital vacuometer (Magnamed, São Paulo, Brazil) with a scale of $300 \mathrm{~cm} \mathrm{H}_{2} \mathrm{O}$ divided into intervals of $0.1 \mathrm{~cm}$ $\mathrm{H}_{2} \mathrm{O}$ and a time interval measure of $0.01 \mathrm{~s}$ was used to measure the $\mathrm{P}_{\operatorname{Imax}}$ and the TIE index. The method used was the occlusion of the airway during inspiration with a unidirectional valve, with the subjects in the supine position and the head elevated at $45^{\circ} .{ }^{13,14}$ The cuff was hyperinflated to prevent air leak during measurement. After tracheal aspiration, subjects remained connected to the mechanical ventilator to rest for 2 min with $\mathrm{F}_{\mathrm{IO}_{2}} 1.0$. $^{5-7,15,16}$

Following hyperoxygenation, the mechanical ventilator was disconnected and, after $10 \mathrm{~s}$ of spontaneous breathing, the digital manometer connector was coupled manually at the end of a normal expiration (at the functional residual 


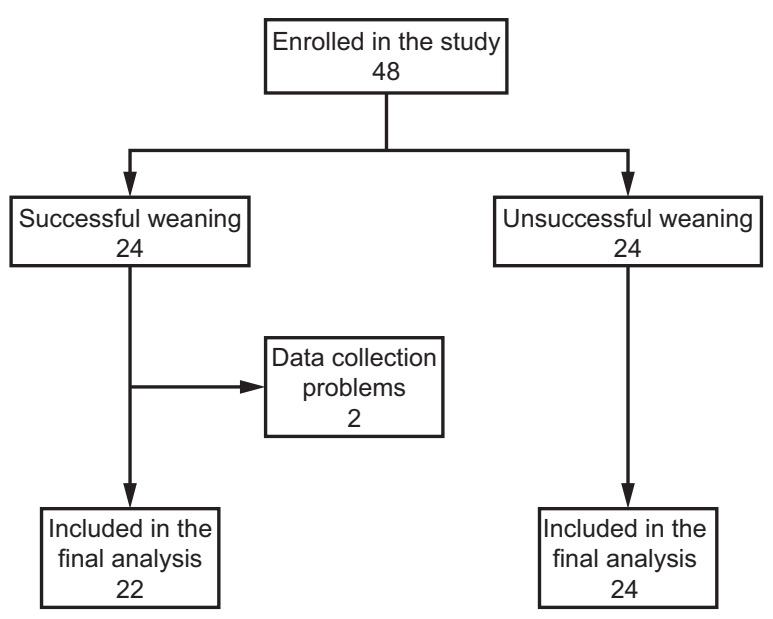

Fig. 1. Flow chart.

capacity level) to the artificial airway, keeping the airway occluded for a 60-s interval while recording the values corresponding to each inspiratory effort. $6,7,13,14,17$

The TIE index was calculated as the ratio of the $\mathrm{P}_{\text {Imax }}$ developed in the last $30 \mathrm{~s}$ of a 60 -s period of airway occlusion with a unidirectional valve to the time demanded to reach that value: TIE index $=\mathrm{P}_{\text {Imax }}(30 \mathrm{~s}$ after start $)$ /time to achieve this value of $\mathrm{P}_{\text {Imax }}$. It should be emphasized that the values of the TIE index were measured but not utilized for the decision to liberate subjects from mechanical ventilation; however, clinicians were not blinded to the results. The decision to liberate was only made after a successful spontaneous breathing trial with a T-piece for $30 \mathrm{~min}$, following the standard ICU protocol.

\section{Procedures for the Capture and Processing the sEMG Signal}

We used sEMG (Miotec, Porto Alegre, Brazil) to capture and process the muscle electrical signal. This device has 4 channels that allow an integrated analysis of up to 4 muscle groups. Silver chloride self-adhesive electrodes were used to record EMG, according to recommendations regarding standardized EMG signal capture. ${ }^{18}$ Signals were captured and automatically potentiated in a frequency capturing a band of 20-500 Hz. The regions for the placement of the electrodes were chosen following recommendations of previous studies. ${ }^{10,15,16,18}$

We selected 4 respiratory muscles to assess the sEMG signals: right diaphragm, right external intercostals, anterior scalene, and sternocleidomastoid. Values were analyzed comparing subjects who succeeded or failed in the ventilatory weaning trial. The root mean square (RMS) in $\mu \mathrm{v} / \mathrm{s}$ was used to measure the magnitude of the sEMG signal and correlated with the generated force and the torque of each muscle. The sEMG data were collected for $60 \mathrm{~s}$ during the TIE index measurement.
The values found for each muscle were pooled and analyzed in each of the $320-\mathrm{s}$ intervals: T1 (0-20 s), T2 (21-40 s), and T3 (41-60 s).

\section{Statistical Analysis}

The sample size was calculated to evaluate differences in the order of $20 \%$ as for the RMS values between the groups with a power of $80 \%$ and an alpha error of $5 \%$, which resulted in a minimum of 36 subjects. Results were expressed as the median (interquartile range) for nonGaussian distribution. Continuous variables were compared with the Mann-Whitney test. More than 2 paired samples were compared with the Friedman analysis of variance complemented by the Wilcoxon test. Categorical variables were expressed as frequencies and differences between them as assessed with chi-square or Fisher exact tests. $P<.05$ was considered significant. Statistical analysis was performed using SPSS 18.0 for Windows (SPSS, Chicago, Illinois).

\section{Results}

The general characteristics of the 46 subjects included in the final analysis are shown in Table 1. The median (interquartile range) ages between groups were comparable at 81 (78-87) y versus $79(49-87)$ y $(P=.24)$. Data for $P_{\text {Imax }}$ and TIE index measurements are shown in Table $2 . \mathrm{P}_{\text {Imax }}$ values increased over time in both the failure $(P<.001)$ and the success groups $(P<.001)$. However, the magnitude of $\mathrm{P}_{\text {Imax }}$ values achieved in successful cases was statistically higher at all times $(P<.001$ for every comparison). The values for the TIE index were also statistically higher in the success group, at $1.3(1.1-2.1)$ versus $0.6(0.6-0.8)(P<$ .001).

In the first step, the RMS values of each group were pooled to represent the respiratory musculature as a whole (Fig. 2). In the second step, the RMS values were analyzed separately for each of the studied muscles: right diaphragm, right external intercostals, anterior scalene, and sternocleidomastoid. Pooled RMS values increased over time in the success and failure of ventilatory liberation. In the failure group, values were statistically different only between T3 and T1, whereas the increase reached statistical differences for every period analyzed in the success group. The RMS values were higher in successful weaning subjects for all 3 periods of observation $(P<.001)$.

Considering the major muscle groups, the median RMS values of the right diaphragm over time were constant in those who failed ventilatory weaning but increased significantly at the end of the observation period in the success group (Fig. 3A). The RMS values were higher in subjects with successful weaning in every 


\section{ResPIRATORy Muscle INVOLVEMENT IN THE TIE INDEX}

Table 1. Subject Characteristics

\begin{tabular}{lccc}
\hline \hline & All & Failure Group & Success Group \\
\hline Gender (male/female) & $26 / 20$ & $12 / 11$ & $14 / 9$ \\
Age, y & $80(71-87)$ & $81(78-87)$ & $79(49-87)$ \\
APACHE II, \% adjusted & $36(24-41)$ & $38(25-41)$ & $35(24-40)$ \\
Artificial airways (orotracheal tube/tracheostomy) & $39 / 7$ & $21 / 3$ & .77 \\
Duration of mechanical ventilation, d & $8(4-10)$ & $8(5-9)$ & .24 \\
Diagnosis at ICU admission & & & .48 \\
$\quad$ Sepsis & 15 & 10 & .59 \\
Stroke & 15 & 5 & .64 \\
Acute respiratory failure & 13 & 7 & .48 \\
Heart failure & 3 & 2 & .87 \\
\end{tabular}

$\overline{\text { Data are presented as } n}$ or mean \pm SD. $N=46$ subjects; failure group: $n=24$; success group: $n=22$.

Table 2. $\quad \mathrm{P}_{\text {Imax }}$ and TIE Index

\begin{tabular}{|c|c|c|}
\hline & Failure Group & Success Group \\
\hline $\mathrm{P}_{\operatorname{Imax}}$ at $\mathrm{T} 1(0-20 \mathrm{~s})$ & $21(12-25)$ & $31(22-41)^{\ddagger}$ \\
\hline $\mathrm{P}_{\mathrm{Imax}}$ at T2 $(21-40 \mathrm{~s})$ & $27(22-33)^{*}$ & $61(40-67)^{* \frac{*}{*}}$ \\
\hline $\mathrm{P}_{\mathrm{Imax}}$ at $\mathrm{T} 3(41-60 \mathrm{~s})$ & $35(30-37)^{* \dagger}$ & $71(51-100)^{*+1}$ \\
\hline TIE index & $0.6(0.6-0.8)$ & $1.3(1.1-2.1)^{\frac{\hbar}{\hbar}}$ \\
\hline \multicolumn{3}{|c|}{$\begin{array}{l}\text { Data are presented as median (interquartile range). } \\
* P<.001 \text { versus } \mathrm{T} 1 \text { of the same group. } \\
{ }^{\dagger} P<.001 \text { versus } \mathrm{T} 2 \text { of the same group. } \\
{ }^{\top} P<.001 \text { versus failure group at the same time interval. } \\
\mathrm{P}_{\mathrm{Imax}}=\text { maximum inspiratory pressure } \\
\mathrm{TIE}=\text { timed inspiratory effort }\end{array}$} \\
\hline
\end{tabular}

observation interval, but statistical significance was only found at T3. For the right external intercostals muscles, the median RMS values over time remained stable in both groups (Fig. 3B), although the magnitude of RMS values was higher in the success group for every $20 \mathrm{~s}$ interval studied.

The behavior of the 2 accessory muscle groups studied was noted as well. The median RMS values for the anterior scalene muscle over time (Fig. 3C) significantly increased over time, but only in the success group; the median RMS for the sternocleidomastoid muscle over time increased in both groups of subjects (Fig. 3D). Finally, values for the success group were significantly higher than in the failure group for every studied 20-s interval between groups of accessory muscles (Fig. 3C and 3D).

\section{Discussion}

When conducting the weaning process, muscle fitness should be taken into account to maintain respiratory autonomy. In this setting, tests that assess muscle strength and endurance may be particularly useful. Accordingly, the TIE index, calculated as the ratio of the $\mathrm{P}_{\text {Imax }}$ to the time demanded to reach that value, is valuable in predicting success in liberation from mechanical ventilation. ${ }^{6,7,13}$

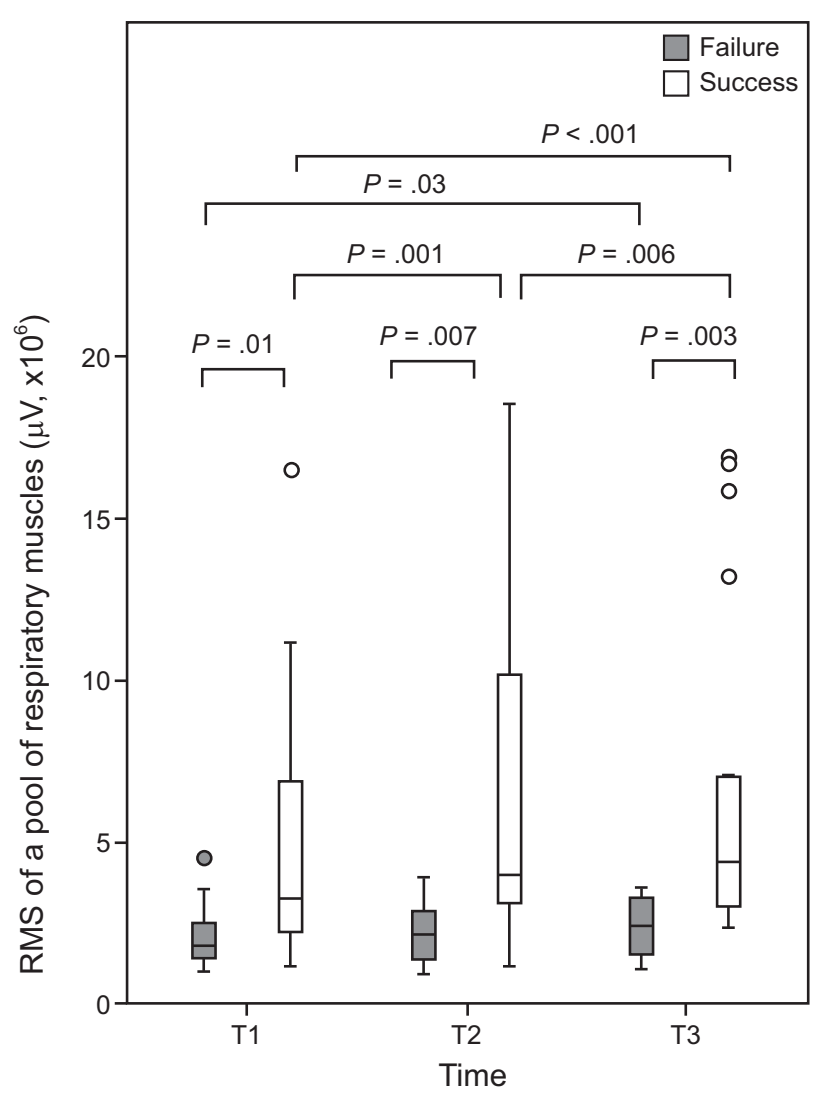

Fig. 2. Medians (interquartile range) of the pooled RMS values, a parameter that assesses muscle strength, of the respiratory muscles in the failure and success groups at T1 (0-20 s), T2 (21-40 s), and T3 (41-60 s). $P<.05$ were considered significant. RMS $=$ root mean square.

The subjects in this study had a median age of $80 \mathrm{y}$, with a higher prevalence of males; these data are similar to the populations treated in ICUs worldwide. ${ }^{19-24}$ Consistent with the literature, age tended to be higher in those who failed weaning $(P=.24)$, a finding that can be explained by the 

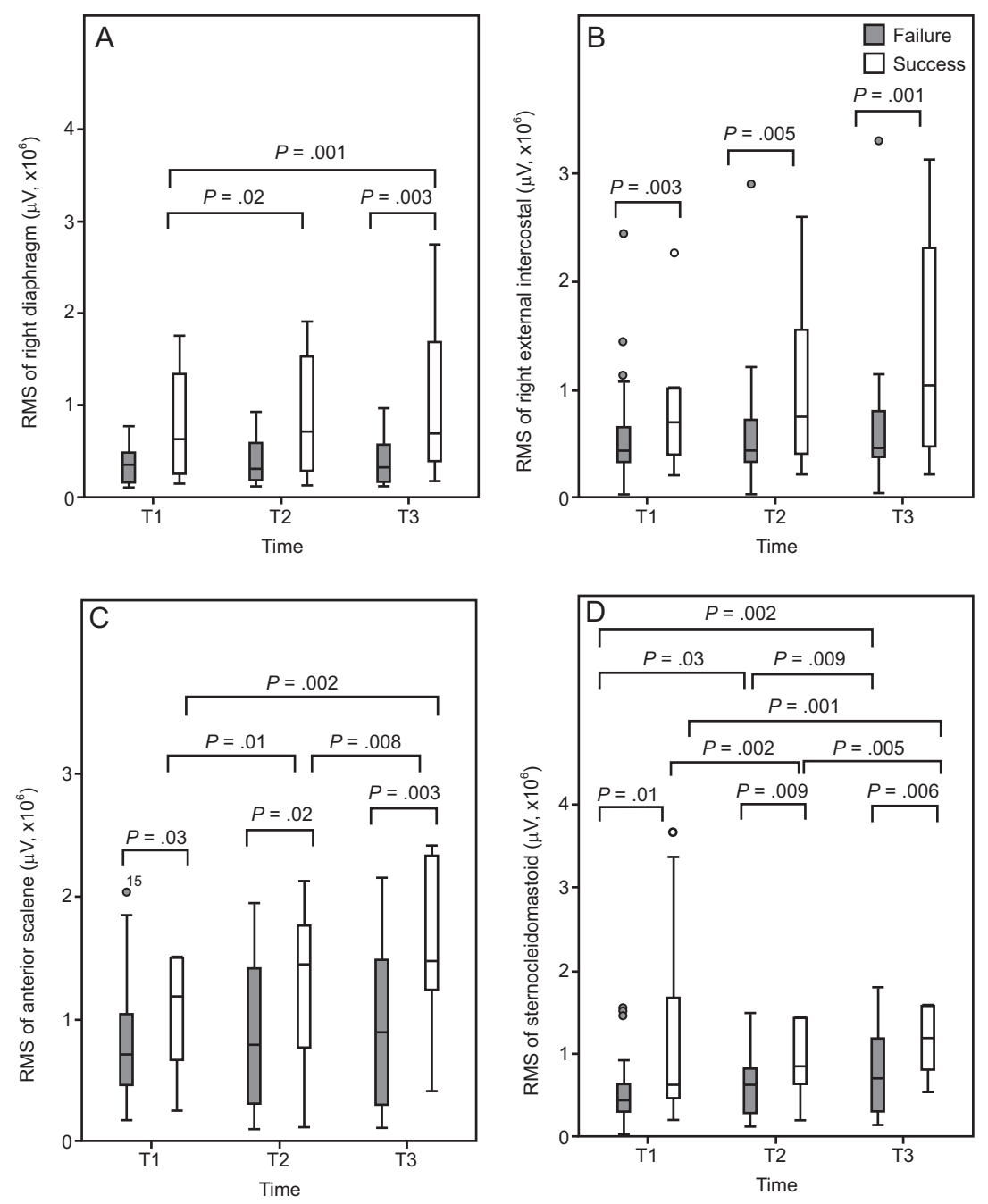

Fig. 3. Medians (interquartile range) of the RMS values, a parameter that assesses muscle strength, of the respiratory muscles in the failure and success groups at T1 (0-20 s), T2 (21-40 s), and T3 (41-60 s). A: Right diaphragm, (B) right external intercostal, (C) anterior scalene, (D) sternocleidomastoid. $P<.05$ were considered significant. $\mathrm{RMS}=$ root mean square.

morphological and functional alteration that affects all the skeletal muscle system by the aging process.

In line with a previous publication, ${ }^{7,14}$ the median $\mathrm{P}_{\text {Imax }}$ values in this study increased over time regardless of the weaning outcome. However, consistent with better muscle performance, the median $\mathrm{P}_{\mathrm{Imax}}$ values at any time were higher in the success group. The median TIE index values were also substantially higher in the success group, which was noted in previous studies. ${ }^{7,13,17}$

The involvement of the muscle groups during the TIE index measurement with sEMG was evaluated using the RMS variable, which has a direct relationship with the degree of motor unit recruitment. ${ }^{25,26}$ When the pooled sEMG results were analyzed, muscle strength increased over time, following the trend observed for $\mathrm{P}_{\text {Imax }}$, irrespective of the analyzed group (Fig. 2). These results are consistent with several previous studies reporting increases in
RMS in circumstances of increased ventilatory demand. ${ }^{10,12}$ In line with the findings regarding $\mathrm{P}_{\mathrm{Imax}}$ values, the RMS medians were statistically higher at every 20 -s interval in the success group. Our findings allow us to conclude that, as a whole, muscle strength was always higher in subjects whose mechanical ventilation liberation was successful, which is in agreement with previous observations correlating muscle dysfunction with weaning failure. ${ }^{2,3}$

The strength of the diaphragm, considered the most important muscle in the core group, increased over time, with values reaching statistically significant differences at the end of the observation period in the success group. In addition, the superiority of RMS values in the successful weaning group were higher in every 20 -s interval, but statistically significant differences were restricted to $\mathrm{T} 1$ and $\mathrm{T} 3$, perhaps due to data scattering. When this same parameter was analyzed for right external intercostals muscles 


\section{ResPIRATORy Muscle INVOLVEMENT IN THE TIE INDEX}

over time, there was no statistically significant strength gain in any group of subjects. At any interval of observation, however, the magnitude of the force was always higher in the success group for both muscles. Our observation affirms that the diaphragm is pivotal for the increase in the $\mathrm{P}_{\text {Imax }}$ in the last $40 \mathrm{~s}$ of the TIE index measurement as reported in previous studies, supporting the concept that diaphragmatic dysfunction induced by mechanical ventilation may impose substantial difficulties on successful liberation from mechanical ventilation. . $^{3,714,17}$

Analysis of the strength of the accessory muscles indicated that the muscle recruitment of the anterior scalene grew over time in both subject groups, but significant differences were only achieved in the success group. Regarding the sternocleidomastoid, both groups of subjects showed significant increases over time. In addition, the strength of the sternocleidomastiod seems to have been decisive for weaning success because there was a substantial increase in RMS values over time after $40 \mathrm{~s}$ of observation, which not observed with the scalenes. Our findings conform to a previous study that stressed the role of the sternocleidomastoid in quiet and forced breathing. ${ }^{8,11,12}$

The study has several limitations. The observed sample was small and predominantly composed of elderly subjects, which limits the generalizability of the findings. In addition, the number of available electromyography channels could be higher, which might increase the sensitivity of the method. Future studies with a larger and younger sample are necessary to better understand ventilatory muscle physiology during the TIE index measurement.

\section{Conclusions}

Our sEMG findings during TIE index measurement indicate that subjects succeeding in a weaning trial had greater muscle strength, a finding that was confirmed in both the pooled muscle analysis and the individual muscle analysis. These findings also suggest that a vigorous diaphragm with low fatigue potential is essential for successful weaning and that the sternocleidomastoid as important as the diaphragm in this regard.

\section{ACKNOWLEDGMENTS}

The authors are grateful to the respiratory physiotherapists and physicians of the ICU of the Hospital Icaraí.

\section{REFERENCES}

1. Lone NI, Walsh TS. Prolonged mechanical ventilation in critically ill patients: epidemiology, outcomes and modelling the potential cost consequences of establishing a regional weaning unit. Crit Care 2011;15(2):R102.

2. Vassilakopoulos T, Petrof BJ. Ventilator-induced diaphragmatic dysfunction. Am J Respir Crit Care Med 2004;169(3):336-341
3. Levine S, Nguyen T, Taylor N, Friscia ME, Budak MT, Rothenberg P, et al. Rapid disuse atrophy of diaphragm fibers in mechanically ventilated humans. N Engl J Med 2008;358(13):1327-1335.

4. Sassoon C. Ventilator-associated diaphragmatic dysfunction. Am J Respir Crit Care Med 2002;166(8):1017-1018.

5. Caruso P, Friedrich C, Denari SD, Ruiz SA, Deheinzelin D. The unidirectional valve is the best method to determine maximal inspiratory pressure during weaning. Chest 1999;115(4):1096-1101.

6. da Silva Guimarães BL, de Souza LC, Guimarães FS, Lugon JR. Serial weekly measurements of the timed inspiratory effort index can predict successful prolonged weaning. Respir Care 2019;64(10):12861292.

7. de Souza LC, da Silva CTJ, Almeida JR, Lugon JR. Comparison of maximal inspiratory pressure, tracheal airway occlusion pressure, and its ratio in the prediction of weaning outcome: impact of the use of a digital vacuometer and the unidirectional valve. Respir Care 2012;57 (8): 1285-1290.

8. Cala SJ, Edyvean J, Engel LA. Chest wall and trunk muscle activity during inspiratory loading. J Appl Physiol. dezembro de 1992;73(6): 2373-2381.

9. Campbell C, Weinger MB, Quinn M. Alterations in diaphragm EMG activity during opiate-induced respiratory depression. Respir Physiol 1995;100(2):107-117.

10. Hawkes EZ, Nowicky AV, McConnell AK. Diaphragm and intercostal surface EMG and muscle performance after acute inspiratory muscle loading. Respir Physiol Neurobiol 2007;155(3):213-219.

11. Hug F, Raux M, Morelot-Panzini C, Similowski T. Surface EMG to assess and quantify upper airway dilators activity during non-invasive ventilation. Respir Physiol Neurobiol 2011;178(2):341-345.

12. Schmidt M, Kindler F, Gottfried SB, Raux M, Hug F, Similowski T, et al. Dyspnea and surface inspiratory electromyograms in mechanically ventilated patients. Intensive Care Med 2013;39(8):1368-1376.

13. Guimarães FS, Alves FF, Constantino SS, Dias CM, Menezes S. Avaliação da pressão inspiratória máxima em pacientes críticos nãocooperativos: comparação entre dois métodos. Rev Bras Fisioter 2007; 11(3):233-238.

14. de Souza LC, Guimaraes FS, Lugon JR. The timed inspiratory effort: a promising index of mechanical ventilation weaning for patients with neurologic or neuromuscular diseases. Respir Care 2015;60(2):231238.

15. de Souza LC, Guimaraes FS, Lugon JR. Evaluation of a new index of mechanical ventilation weaning: the timed inspiratory effort. J Intensive Care Med 2015;30(1):37-43.

16. Nadiv Y, Vachbroit R, Gefen A, Elad D, Zaretsky U, Moran D, et al. Evaluation of fatigue of respiratory and lower limb muscles during prolonged aerobic exercise. J Appl Biomech 2012;28(2):139-147.

17. Maarsingh EJ, van Eykern LA, Sprikkelman AB, Hoekstra MO, van Aalderen WM. Respiratory muscle activity measured with a noninvasive EMG technique: technical aspects and reproducibility. J Appl Physiol 2000;88(6): 1955-1961.

18. Duiverman ML, van Eykern LA, Vennik PW, Koeter GH, Maarsingh EJW, Wijkstra PJ. Reproducibility and responsiveness of a noninvasive EMG technique of the respiratory muscles in COPD patients and in healthy subjects. J Appl Physiol 2004;96(5):1723-1729.

19. Damasceno M, David CMN, Souza P, Chiavone PA, Cardoso LTQ, Amaral JLG, et al. Ventilação mecânica no Brasil: aspectos epidemiológicos. Rev Bras Ter Intensiva 2006;18(3):219-228.

20. Genga KR, Russell JA. Update of sepsis in the intensive care unit. J Innate Immun 2017;9(5):441-455.

21. Corbellini C, Trevisan CBE, Villafañe JH, Da Costa AD, Vieira S Weaning from mechanical ventilation: a cross-sectional study of reference values and the discriminative validity of aging. J Phys Ther Sci 2015;27(6):1945-1950. 


\section{ReSPIRATORy Muscle INVOLVEMENT IN THE TIE INDEX}

22. Tanaka T, Miyamoto N, Kozu R, Satomi K, Honda S, Senjyu H. Physical function traits of long-term officially acknowledged victims of pollution-related illnesses compared with elderly patients with chronic obstructive pulmonary disease. J Phys Ther Sci 2014;26(10):1605-1608.

23. Narici M, Franchi M, Maganaris C. Muscle structural assembly and functional consequences. J Exp Biol 2016;219(Pt 2):276-284.

24. Vasilaki A, Richardson A, Van Remmen H, Brooks SV, Larkin L, McArdle A, et al. Role of nerve-muscle interactions and reactive oxygen species in regulation of muscle proteostasis with ageing. $\mathrm{J}$ Physiol (Lond) 2017;595(20):6409-6415.

25. Brown SHM, McGill SM. Co-activation alters the linear versus nonlinear impression of the EMG-torque relationship of trunk muscles. J Biomech 2008;41(3):491-497.

26. Anders C, Brose G, Hofmann GO, Scholle H-C. Evaluation of the EMG-force relationship of trunk muscles during whole body tilt. J Biomech 2008;41(2):333-339. 